\title{
INFLUENCE OF MOISTURE CONTENT ON THE APPLICATION OF ND AND MD TESTS TO VARIOUS SPECIES OF TIMBER ELEMENTS
}

\author{
M.R. VALLUZZI ${ }^{*}$, F. CASARIN ${ }^{2}$, L. SCANCELLI ${ }^{2}$, M. DRDÁCKÝ ${ }^{3}$, M. KLOIBER ${ }^{3}$ \\ AND J. HRIVNÁK ${ }^{3}$ \\ ${ }^{1}$ Department of Cultural Heritage \\ University of Padova \\ Piazza Capitaniato 7, 35139 Padova, Italy \\ e-mail: mariarosa.valluzzi@unipd.it (*corresponding author) \\ ${ }^{2}$ Expin s.r.l. \\ Via Panà 56ter, 35027 Noventa Padovana (PD), Italy \\ e-mail: casarin@expin.it, scancelli@expin.it,www.expin.it

\footnotetext{
${ }^{3}$ Institute of Theoretical and Applied Mechanics (ITAM) of the Czech Academy of Sciences

Prosecká 809/76, 19000 Prague 9, Czech Republic

e-mail: drdacky@itam.cas.cz, kloiber@itam.cas.cz, hrivnak@itam.cas.cz
}

Keywords: Timber species, moisture content, resistance drilling, ultrasonic tests, pin-pushing test, correlation

\begin{abstract}
Variations in environmental conditions can affect the structural performance of timber components and constructions. Especially in case of historic masonry buildings, where timber elements can be found either in roof or floor structures, intrinsic defects (e.g., knots, cracks, degradation), as well as the surrounding environmental conditions (e.g., temperature and moisture) can play an important role in the assessment of the mechanical response of the elements. In this connection, non-destructive (ND) and minor-destructive (MD) procedures are used to investigate the onsite conditions of wood, which are commonly based on either tool penetration resistance or wave transmission devices. In the paper, the influence of moisture content (MC) measured with various devices on a series of both old and new timber elements was compared. The elements made of various wood species (mainly red fir, but also white fir, pine and larch) were subjected to laboratory ND and MD testing by three research groups. Results showed the low influence of the MC on MD tests (i.e., resistance drilling and pin penetration) in comparison to the ND (i.e., sonic/ultrasonic) ones. Correlation relationships are provided, which illustrate and approximatively quantify the effect of MC for the experimentally investigated conditions and test equipment.
\end{abstract}

\section{INTRODUCTION}

Investigation of timber structures relies on both visual and instrumental inspections, the latter based on both non-destructive (ND) and minor-destructive (MD) test procedures [1] [2]. ND and MD tests are basically local tests which can qualify a parameter in a small portion of the 
material but whose results are not representative over an overall element. Moreover, as well known, outcomes are affected by many aspects, among which moisture content (MC) is one of the most sensitive for wood [3] from the site condition viewpoint. The 'oven dry' procedure [1] is recognized as the most effective way to measure the MC in wood. Nevertheless, being it a destructive method, usually moisture meters are used onsite to manually check that parameter.

The paper compares the results obtained by the application of various ND and MD methods to a series of deteriorated timber beam elements retrieved from existing structures (19 components over 21, made of fir, oak, elm, and pine) and 12 new ones (made of fir and larch).

Experimental tests were performed by research groups of the University of Padova (UNIPD), Italy and the UNIPD's spin-off Expin srl, and the Institute of Theoretical and Applied Mechanics of Prague, Czech Republic (ITAM).

Results were compared by grouping similar methods, i.e.: resistance drilling (two types of Resistograph ${ }^{\circledR}$, one for each group), pin penetration (Novatester device for UNIPD and the pin pushing device for ITAM), wave velocity-based methods (ultrasonic for UNIPD and stress wave for ITAM) [4]. Pin pushing is an in-house new MD device provided patented by ITAM, which is able to gradually apply, monitor and record the force occurring for the pin penetration into the wood [5]. Three types of moisture measurement devices were used (two electric and one electromagnetic).

The research aims are: i) to contribute on the quantification of the influence of MC according to different devices applied to various species in different conditions, and ii) to evaluate the possible MC effect on the results provided by the application of common ND/MD testing methods for the onsite in

The problem has alr wood specimens - spruc
pushing [6] and the min
were carried out using 3 investigat
ready bee
uce boards
n-jack [7
30 spruce ation in existing
een partially stu
ds. Thus ysing
[7] behavior has
ce boards at mo
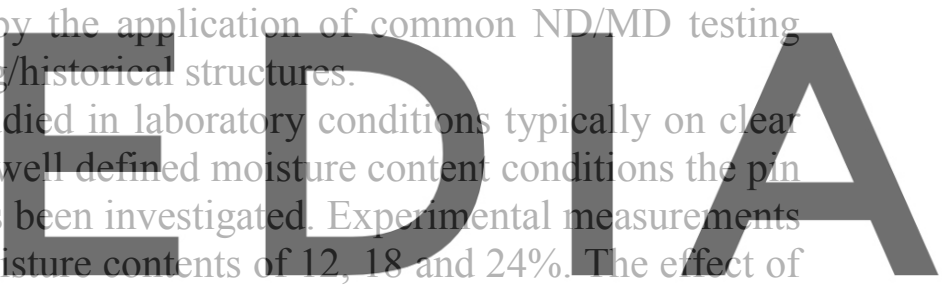

the wood moisture on the measurement by means of the both devices was confirmed. In the

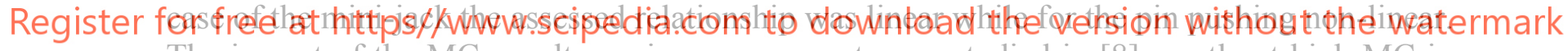

The impact of the MC on ultrasonic measurements was studied in [8] mostly at high MC in artificial climate chamber environment. It has been found that velocity decreases sharply as the moisture content increases from $0 \%$ to the fiber saturation point of $30 \%$, and then decreases at a much slower rate as the MC increases further.

However, the effect of the moisture content at ND/MD measurements has not been so frequently studied because these methods are mostly applied for investigation of built-in timber in buildings where the MC does not vary significantly and the other wood parameters (e.g. species, structure, defects etc.) influence much more the measurement results.

\section{EXPERIMENTAL CAMPAIGN}

Several experimental procedures were applied to either new or old timber elements. The former all had rectangular cross-section of $160 \times 160 \mathrm{~mm}^{2}$, length of about $5 \mathrm{~m}$ and were equally distributed between larch and red fir woods (six elements for each wood type), whereas the latter were retrieved from a roof dismantled from an existing masonry buildings and were therefore suffering decay conditions. These old elements had not homogeneous dimensions for cross-sections (mostly larger than the new elements) and lengths (from about 3 to $5 \mathrm{~m}$ ) and 
belonged to various species (mainly red fir, but also few elements were made of pine, white fir, oak and elm).

The new elements were already classified as C24, according to UNI EN 338 (2016) [9]. The retrieved beams were affected by the presence of cracks (e.g., R-RF_4 and R-RF_10 beams) and quite diffused single and groups of knots, and presented a slope (of about $10 \%$ ) of grain in tangential sections. Therefore, they resulted in categories I, II or III (or non-classifiable, in few cases, due to high deteriorated conditions), according to the onsite increasing grades (form I to III) provided by UNI 11119 (2004) [10]. Just to compare the two sets of components (new and old) for the fir specie, a new element would have a bending strength of $24 \mathrm{MPa}$ and a parallel bending modulus of elasticity of $11000 \mathrm{MPa}$ (according to [9]), whereas an old one would refer to decreasing values for I-II-II grades of 11,5-10,0-7,5 MPa and 13000-12000-11000 MPa for the bending strength and modulus of elasticity, respectively (according to [10]).

Figure 1 shows some examples of the types of beams considered in the study.

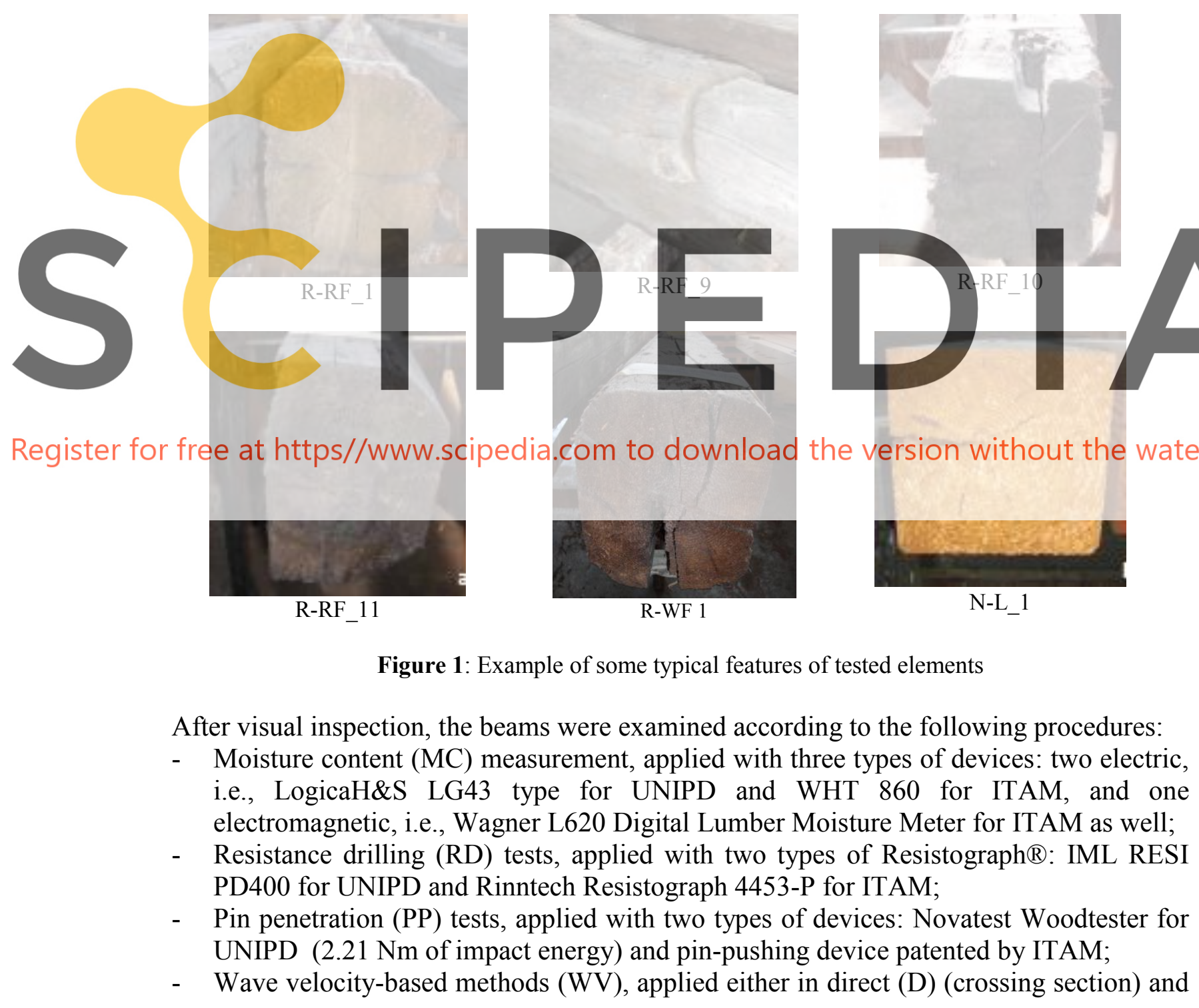


indirect (I) (longitudinal on the surface) configurations, i.e., ultrasonic wave for UNIPD (Proceq Pundit Lab + device) and sonic stress wave for ITAM (Fakopp Microsecond Timer tool).

Moisture meters are based on the correlation of electric resistance and water content on the wood: the higher is the electric resistance the lower is the MC. Moisture meters can be either pin meter (electric) or pinless meter (electromagnetic). The measurements with pin meters are carried out on two points of about $20 \mathrm{~mm}$ spaced. Pinless moisture meters are completely ND: they use electrical waves at a certain electromagnetic frequency, which are transmitted through the base pad in contact with the wood. Moisture meters can give reliable results in a range of humidity of $7-30 \%$, i.e. below the saturation point of the wood [11]. They are calibrated for non-damaged wood structures, therefore, they provide more precise and coherent data for the sound wood than for the wood with deteriorated structure of cells by fungi or worms.

Resistance drilling devices measure the energy consumption to allow a thin needle (about 1.5-3 $\mathrm{mm}$ in diameter and over $400 \mathrm{~mm}$ long) to be driven in the wood [3]. The test outcomes are the density profiles of the penetrated section of wood, which can indicate the condition of the material and identify possible inner defects or voids.

Pin penetration tests apply a needle impact from the surface of wood and can investigate the wood up to few $\mathrm{cm}$ in depth [3]. The device used by UNIPD had a needle of $5 \mathrm{~mm}$ in diameter; five consecutive strikes were applied to the element and a displacement transducer measured the reached depth, which can be correlated to variations of density along the element. Instead, the pin-pushing tests results were the average forces that allow the pin (about 25 mmin diameter
and $120 \mathrm{~mm}$ long) to penetrate into the wood [5].
Test methods based on either sonic or ultras onic wave velocities measure the time occurring
the wave to be transferred from two points of an element, those points being either on opposite
sides (direct tests) or on the same side (indirect tests) [12]. The former configuration
investigates the cross-section of an element, the latter mainly the surface of it. The higher is the density of the material the higher is the wave velocity. Usually, due to the cellular structure of

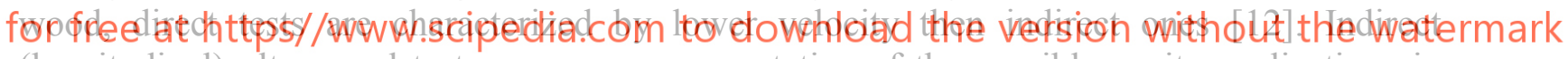
(longitudinal) ultrasound tests are more representative of the possible onsite applications in buildings due to possible problems of accessibility to some sides of the structural elements.

Table 1 shows the characteristics of all the timber elements and the number of tests (i.e., measurement points on the beams) carried out for each procedure applied by the research groups (numbers are shown as UNIPD+ITAM measurement points). Notations for labels: R stands for 'recovered', N for 'new'; RF stands for 'red fir', WF for 'white fir', L for 'larch', P for 'pine'.

Station points were distributed along two faces of the elements, as in the examples showed in Figure 2. MC was measured along with the other ND/MD tests. All the various tests (MC, $\mathrm{RD}, \mathrm{PP}, \mathrm{SW}$ ) were performed on the same points along the elements (see Figure 2). As for SW, direct tests were carried out from one of the points mentioned above to the corresponding one on the opposite side (three measures for each pair); indirect tests were performed on three sides of the elements, i.e., two pairs starting from $1 \mathrm{~m}$ from the two ends and one pair from the center of the element (three measures for each pair spaced of 100, 150, 200, 300, 450 and $600 \mathrm{~mm}$ ). 
Table 1: Experimental program and description of specimens

\begin{tabular}{|c|c|c|c|c|c|c|c|c|c|}
\hline \multirow{2}{*}{$\begin{array}{c}\text { Element } \\
\text { label }\end{array}$} & \multicolumn{2}{|c|}{ Cross-section } & \multirow{2}{*}{$\begin{array}{l}\text { Length } \\
{[\mathrm{mm}]}\end{array}$} & \multirow[b]{2}{*}{ Classification } & \multirow[b]{2}{*}{$\mathrm{MC}$} & \multirow[b]{2}{*}{$\mathrm{RD}$} & \multirow[b]{2}{*}{ PP } & \multicolumn{2}{|c|}{ WV } \\
\hline & $\begin{array}{c}\text { Dimensions } \\
{\left[\mathrm{mm}^{2}\right]}\end{array}$ & Type & & & & & & $\mathrm{D}$ & I \\
\hline R-RF_1 & $221 \times 185$ & $\begin{array}{l}\text { quite } \\
\text { regular }\end{array}$ & 4030 & II grade & $17+2$ & $17+2$ & $17+2$ & $0+2$ & $0+2$ \\
\hline R-RF_2 & $175 \times 160$ & $\begin{array}{c}\text { quite } \\
\text { circular }\end{array}$ & 4600 & II grade & $9+2$ & $9+2$ & $9+2$ & $9+2$ & $18+2$ \\
\hline R-RF 3 & $220 \times 152$ & regular & 4500 & I grade & $10+2$ & $10+2$ & $10+2$ & $7+2$ & $18+2$ \\
\hline R-RF 4 & $224 \times 171$ & regular & 4810 & n.c. & $12+2$ & $12+2$ & $12+2$ & $0+2$ & $0+2$ \\
\hline R-RF_5 & $250 \times 220$ & regular & 4980 & I grade & $11+2$ & $11+2$ & $11+2$ & $8+2$ & $10+2$ \\
\hline R-RF_6 & $223 \times 183$ & regular & 2980 & I grade & $11+2$ & $11+2$ & $11+2$ & $0+2$ & $0+2$ \\
\hline R-RF_7 & $258 \times 214$ & regular & 4230 & I grade & $6+2$ & $6+2$ & $6+2$ & $0+2$ & $10+2$ \\
\hline R-RF_ 8 & $207 \times 162$ & regular & 4625 & I grade & $6+2$ & $10+2$ & $10+2$ & $3+2$ & $0+2$ \\
\hline R-RF_9 & $234 \times 215$ & $\begin{array}{c}\text { quite } \\
\text { circular }\end{array}$ & 4030 & I grade & $7+2$ & $7+2$ & $7+2$ & $0+2$ & $0+2$ \\
\hline $\begin{array}{c}\text { R- } \\
\text { RF } 10 \\
\end{array}$ & $199 \times 158$ & regular & 4680 & n.c. & $18+2$ & $18+2$ & $18+2$ & $18+2$ & $18+2$ \\
\hline $\begin{array}{c}\mathrm{R}- \\
\mathrm{RF}=11\end{array}$ & $194 \times 125$ & trapezoidal & 4530 & I grade & $17+2$ & $17+2$ & $17+2$ & $7+2$ & $18+2$ \\
\hline $\begin{array}{c}\text { R- } \\
\text { RF_12 }\end{array}$ & $214 \times 175$ & regular & 4670 & II grade & $17+2$ & $17+2$ & $17+2$ & $0+2$ & $0+2$ \\
\hline $\begin{array}{c}\mathrm{R}- \\
\mathrm{RF} \\
=13\end{array}$ & $201 \times 135$ & regh & & & & & & & $18+2$ \\
\hline $\begin{array}{c}\text { R- } \\
\text { RF } 14\end{array}$ & $220 \times 178$ & regula & & & 17 & $17+2$ & & & \\
\hline
\end{tabular}

Register forlfree at https//www.scipedia.com to download the version without the watermark

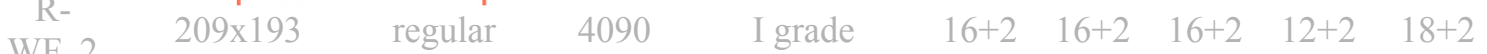

\begin{tabular}{cccccccccc}
\hline R-P_1 & $248 \times 225$ & regular & 5030 & I grade & $6+2$ & $6+2$ & $6+2$ & $10+2$ & $18+2$ \\
\hline R-P_2 & $225 \times 248$ & regular & 4570 & I grade & $17+4$ & $17+4$ & $17+4$ & $0+4$ & $18+4$ \\
\hline N-RF_1 & $160 \times 160$ & regular & 5075 & C24 & $20+2$ & $20+2$ & $20+2$ & $20+2$ & $18+2$ \\
\hline N-RF_2 & $160 \times 160$ & regular & 5090 & C24 & $2+2$ & $20+2$ & $20+2$ & $20+2$ & $18+2$ \\
\hline N-RF_3 & $160 \times 160$ & regular & 5085 & C24 & $2+2$ & $20+2$ & $20+2$ & $20+2$ & $18+2$ \\
\hline N-RF_4 & $160 \times 160$ & regular & 5085 & C24 & $20+2$ & $20+2$ & $20+2$ & $20+2$ & $18+2$ \\
\hline N-RF_5 & $160 \times 160$ & regular & 5085 & C24 & $2+2$ & $20+2$ & $20+2$ & $20+2$ & $18+2$ \\
\hline N-RF_6 & $160 \times 160$ & regular & 5085 & C24 & $2+2$ & $20+2$ & $20+2$ & $20+2$ & $18+2$ \\
\hline N-L_1 & $160 \times 160$ & regular & 5090 & C24 & $2+3$ & $20+2$ & $20+2$ & $20+2$ & $18+2$ \\
\hline N-L_2 & $160 \times 160$ & regular & 5090 & C24 & $2+2$ & $20+2$ & $20+2$ & $20+2$ & $18+2$ \\
\hline N-L_3 & $160 \times 160$ & regular & 5085 & C24 & $20+3$ & $20+2$ & $20+2$ & $20+2$ & $18+2$ \\
\hline N-L_4 & $160 \times 160$ & regular & 5100 & C24 & $20+3$ & $20+2$ & $20+2$ & $20+2$ & $18+2$ \\
\hline N-L_5 & $160 \times 160$ & regular & 5080 & C24 & $2+3$ & $20+2$ & $20+2$ & $20+2$ & $18+2$ \\
\hline N-L_6 & $160 \times 160$ & regular & 5085 & C24 & $2+3$ & $20+2$ & $20+2$ & $20+2$ & $18+2$ \\
\hline
\end{tabular}




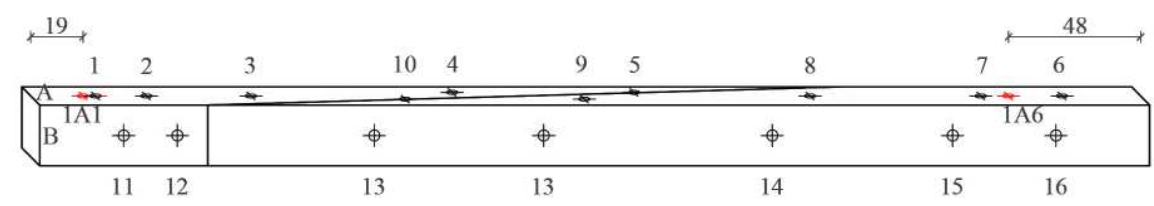

$\mathrm{R}_{-} \mathrm{RF}_{-} 1$

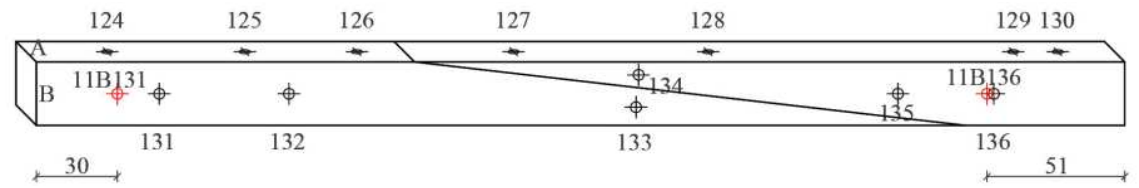

R-RF_9

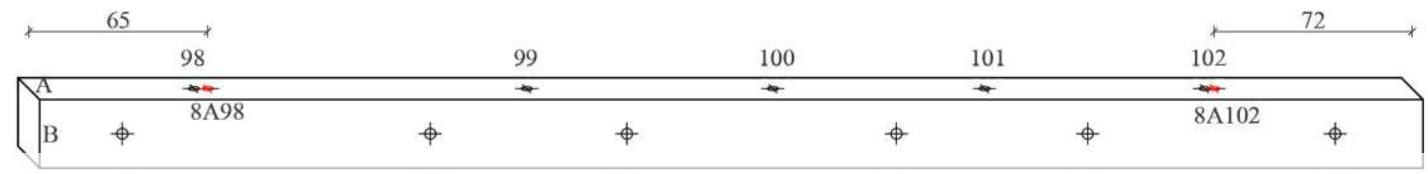
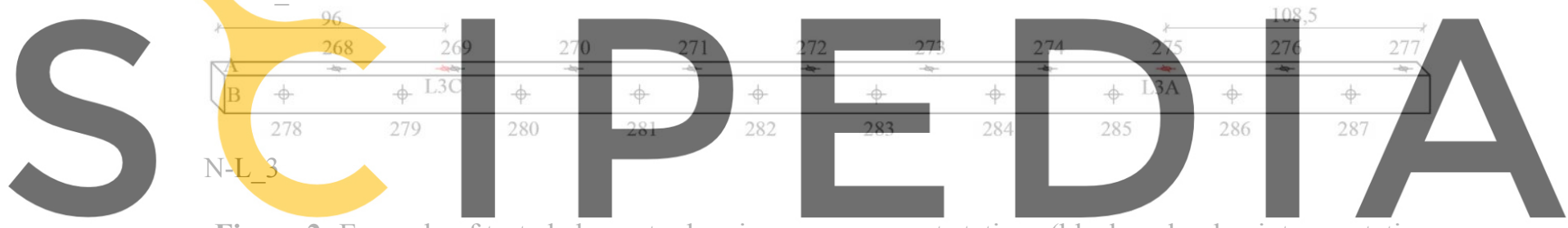

Figure 2: Example of tested elements showing measurement stations (black and red points are stations

Register for free at https//WWWW.Scipedia.com to download the version without the watermark

\section{RESULTS}

Figure 3 and Figure 4 show the distribution of $\mathrm{MC}$ values according to tests performed on the old and new timber elements, respectively. Values vary from $8.5 \%$ to $22.2 \%$ (ITAM) and from $16.8 \%$ to $68.5 \%$ (UNIPD), thus denoting high moisture content conditions in the elements. Many RF old elements were stored outside and were therefore exposed to some rain before storing them in the laboratory; this affected their integrity and, consequently, the experimental results. Highest values of MC concerned retrieved elements $(68 \%$ detected in R-RF_5 from UNIPD and 22.2\% detected in R-P_ 2 from ITAM), whereas in new elements ranges of $17 \%$ $28 \%$ (UNIPD) and 11.2\%-18\% (ITAM) were detected (highest values refer to N-L_6 for both research groups). The differences between results obtained by UNIPD and ITAM were probably due to the different type of moisture meters. The device used by UNIPD was a pin meter able to measure $\mathrm{MC}$ values up to $3 \mathrm{~cm}$ in depth from the surface, while both the devices used by ITAM measured the MC values on the surface of the elements. In fact, the comparison of the average values (Table 2 and Figure 5) showed a good agreement between the electric and electromagnetic methods used by ITAM (see also Figure 6). Results also showed MC measurements in new elements more stable than for the old ones. 


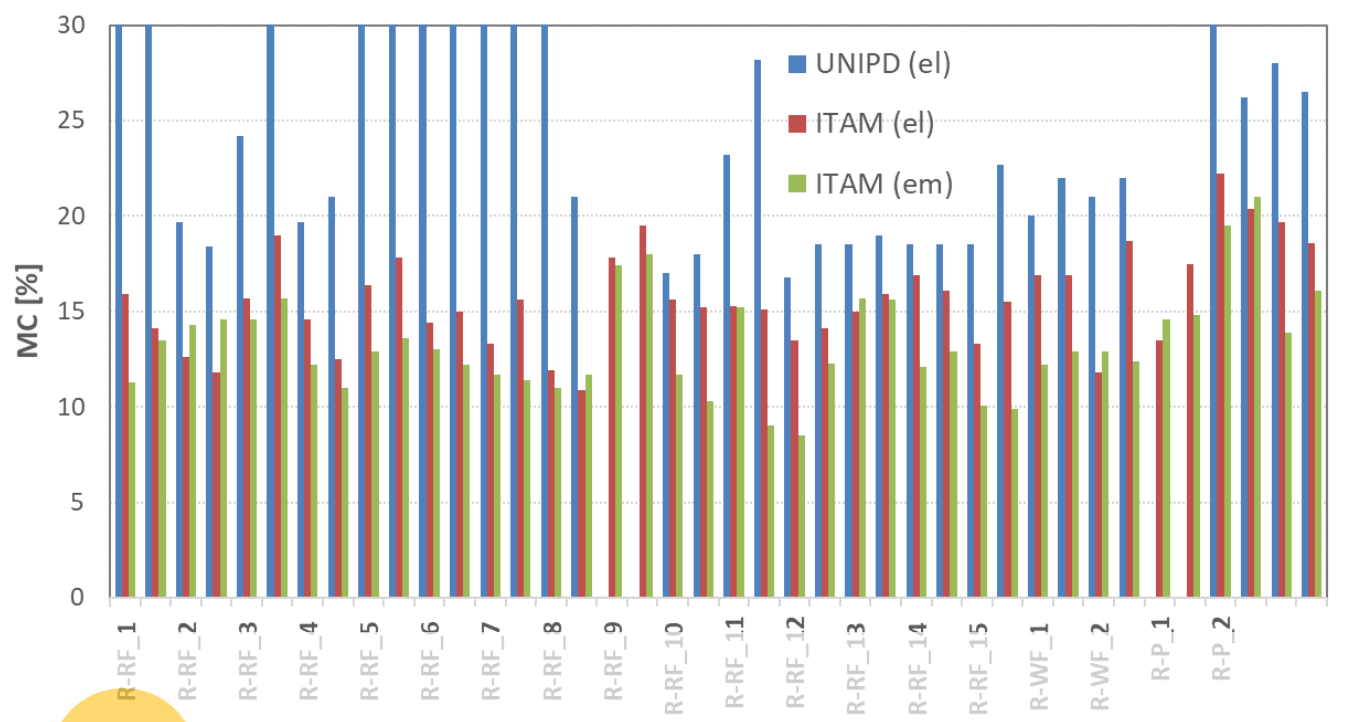

Figure 3: Moisture content measured on old timber elements (values higher than $30 \%$ are cut from graph)
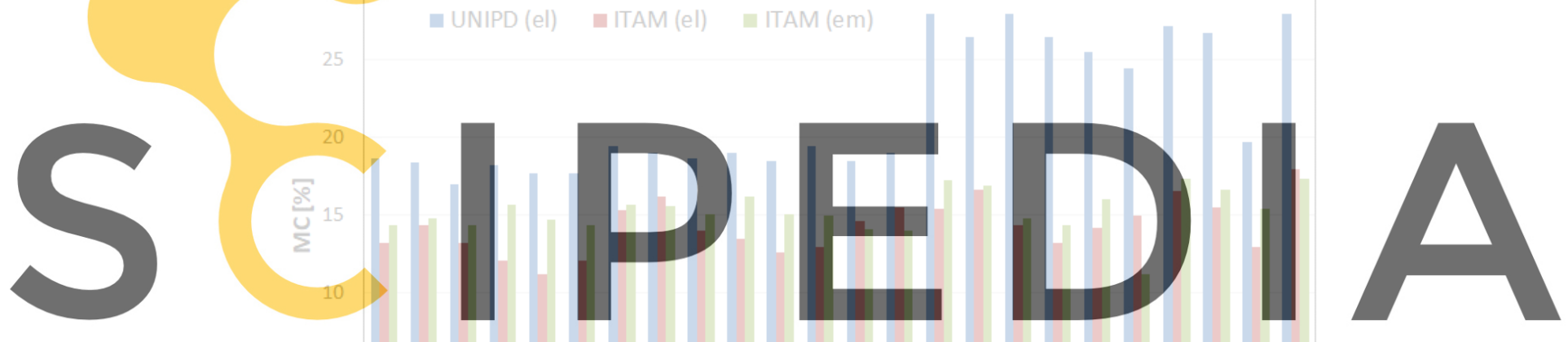

Register for free at https//www.scipedia.com to download the version without the watermark

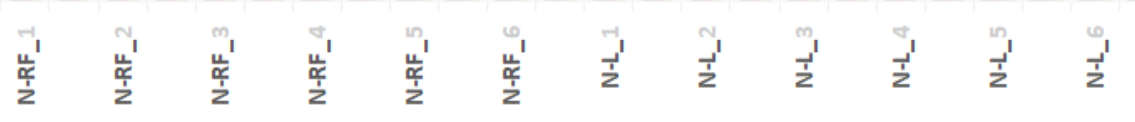

Figure 4: Moisture content measured on new timber elements

Table 2: Moisture content on elements measured with electrical (el) and electromagnetic (em) devices: average values and $\mathrm{CoV}$ (in brackets)

\begin{tabular}{ccccc}
\hline & UNIPD $(\mathrm{el})$ & ITAM $(\mathrm{el})$ & ITAM $(\mathrm{em})$ & Average $(\mathrm{all})$ \\
\hline $\mathrm{R}-\mathrm{RF}$ & $22.17(0.24)$ & $15.01(0.14)$ & $12.78(0.18)$ & $16.65(0.29)$ \\
\hline $\mathrm{R}-W F$ & $21.25(0.05)$ & $16.08(0.18)$ & $12.60(0.03)$ & $16.64(0.26)$ \\
\hline R-P & $28.35(0.11)$ & $18.65(0.16)$ & $16.65(0.18)$ & $21.22(0.29)$ \\
\hline N-RF & $18.49(0.04)$ & $13.94(0.10)$ & $15.21(0.04)$ & $15.88(0.15)$ \\
\hline N-L & $24.84(0.15)$ & $15.18(0.10)$ & $15.41(0.12)$ & $18.48(0.30)$ \\
\hline
\end{tabular}



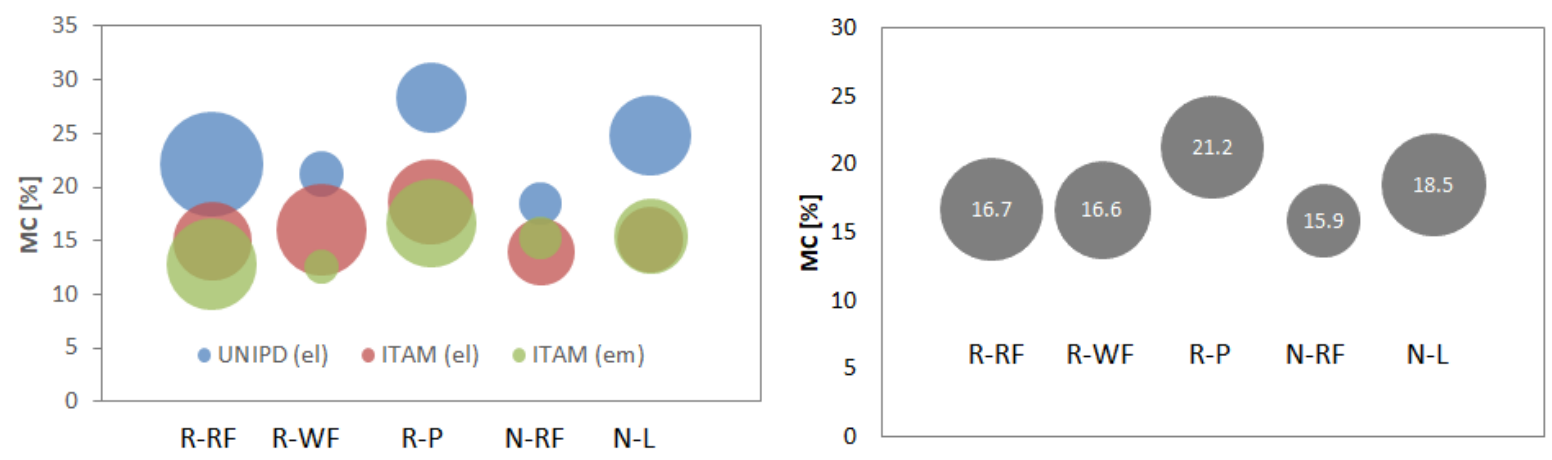

Figure 5: Average values of MC measured on all timber elements

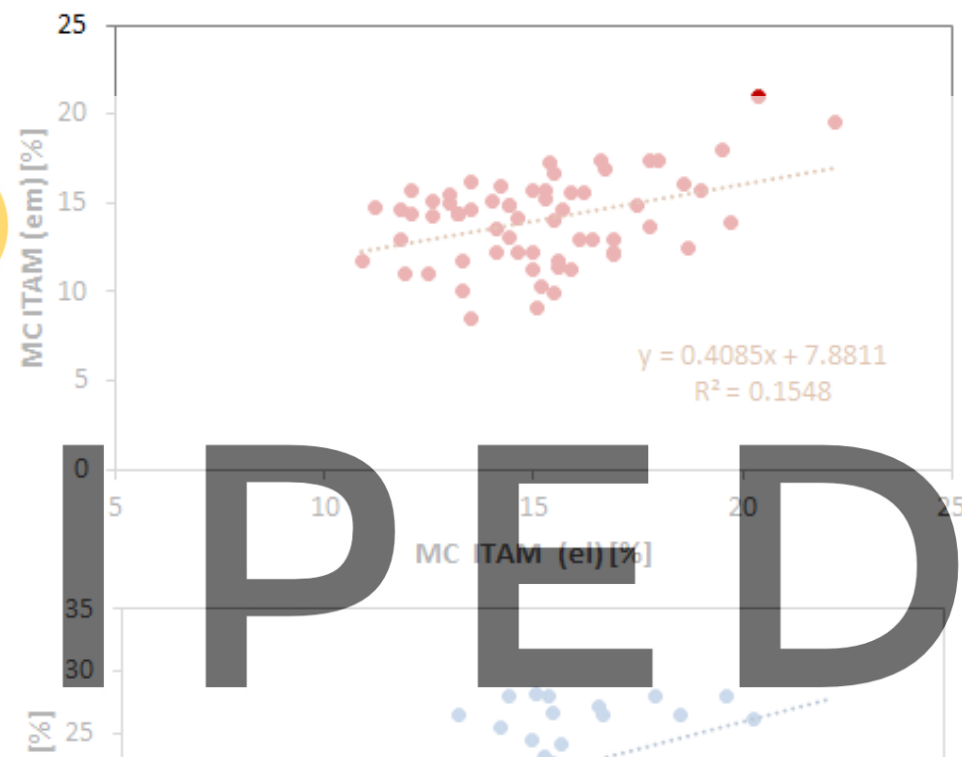

Register for free at https/每www.scipedia.com to downtoad the version without the watermark

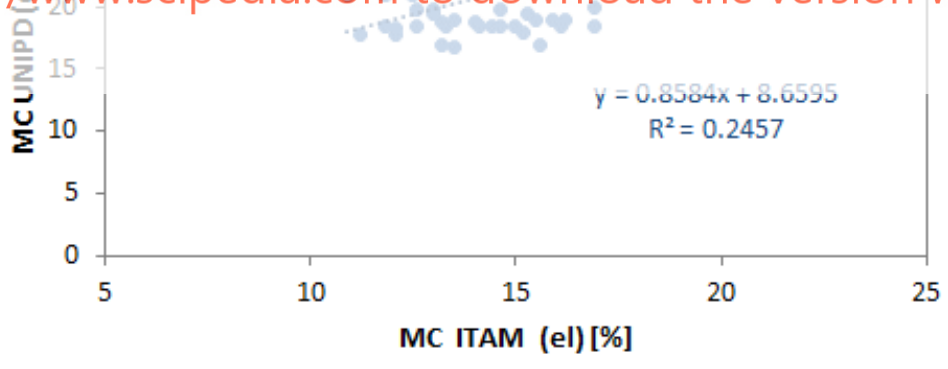

Figure 6: Correlation of MC values measured with different devices on timber elements (values higher than $30 \%$ are not included in graph)

Results were also compared by taking into consideration the station points (mostly positioned close to the ends of elements, see Figure 2) used by UNIPD and ITAM according to the ND/MD test procedures (see Table 1). The high-deteriorated conditions of most of the old beams also affected the pin penetration tests: when less than five strikes were possible, a proportion was made to compare the values among the tested elements, taking into consideration the energy transmitted by the device at each strike. In general, no significant 
influence of MC was detected for both RD and PP test results (Figure 7 and Figure 8). WV tests were more affected by $\mathrm{MC}$ variations, especially in the case of superficial (indirect) tests (Figure 9 and Figure 10), where a general decreasing trend (for increasing MC) was detected. Correlation coefficients were negligible for RD and PP tests; for WV, although not high coefficients were achieved, their values denoted a mutual influence between the transmitted wave velocities and the humidity rate measured in the elements.

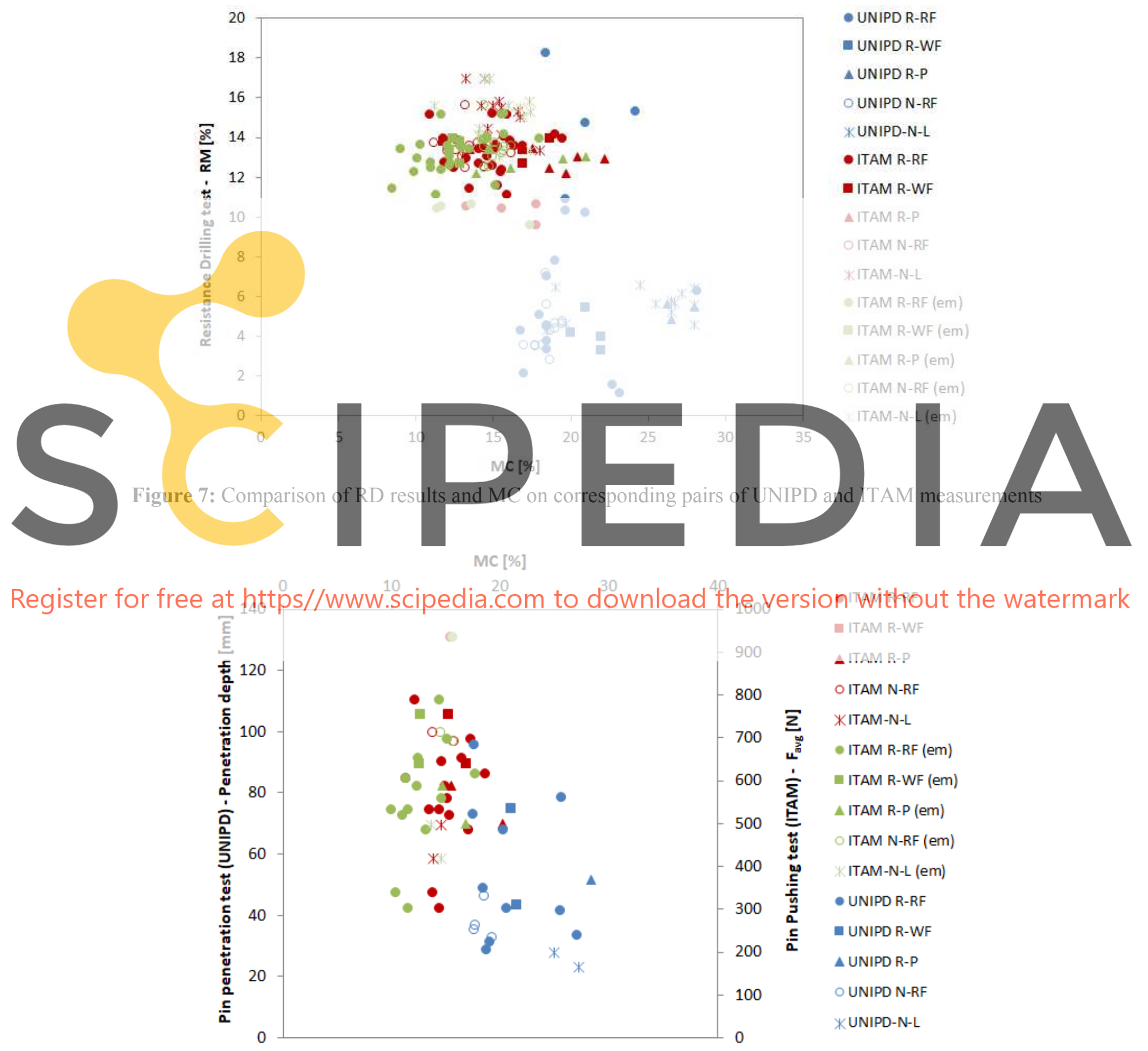

Figure 8: Comparison of PP results and MC on corresponding pairs of UNIPD and ITAM measurements 


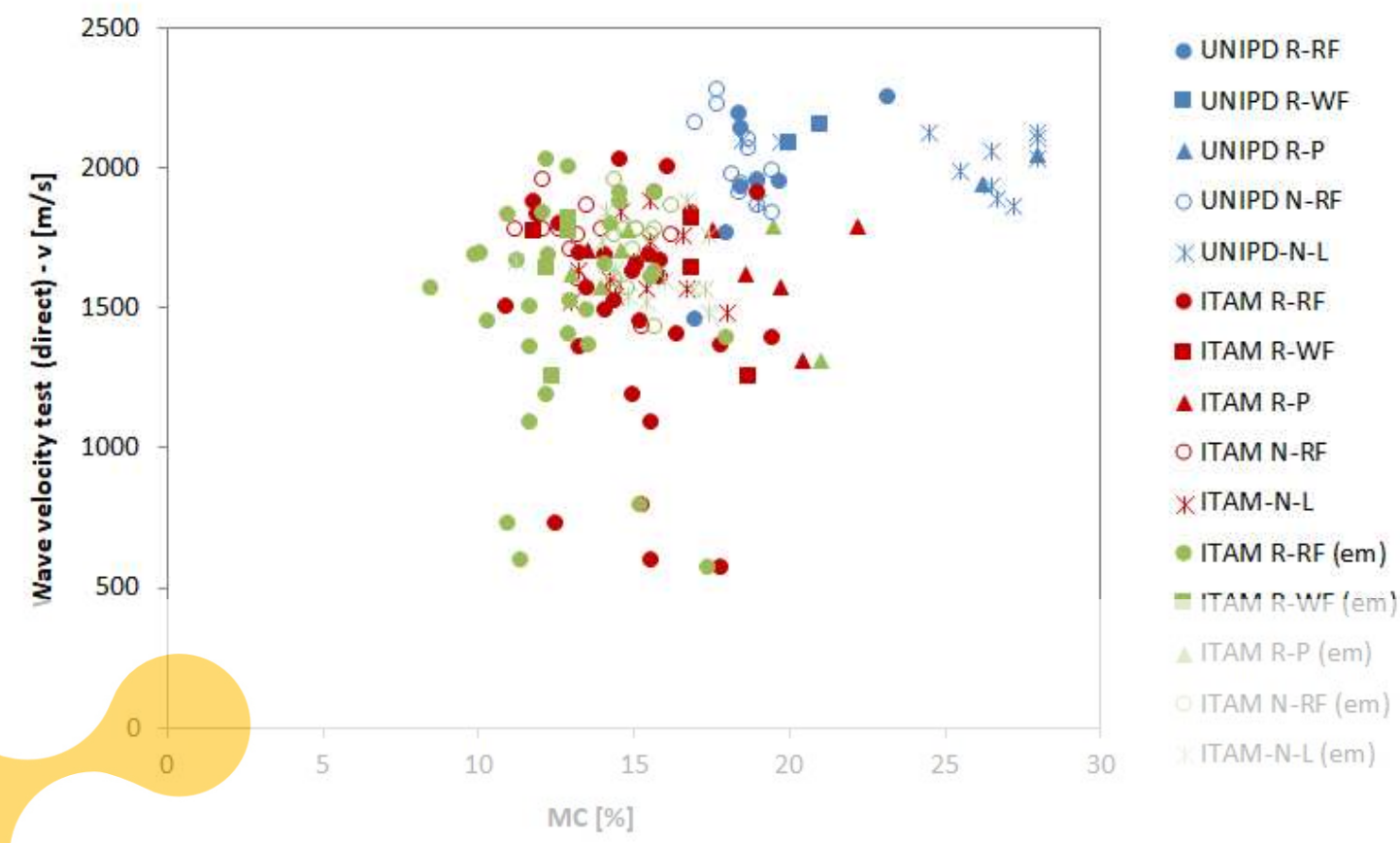

Figure 9: Comparison of WV (direct tests) results and MC on corresponding pairs of UNIPD and ITAM
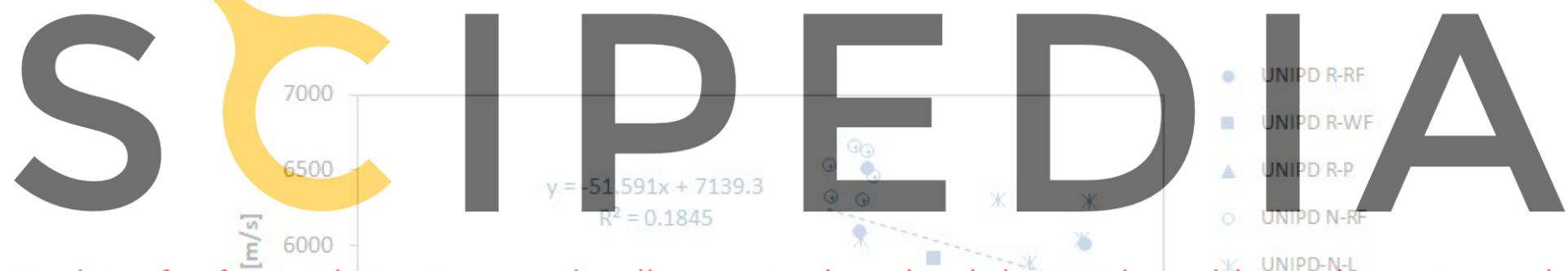

Register for frèe at https//www.scipedia.com to download the version without the watermark
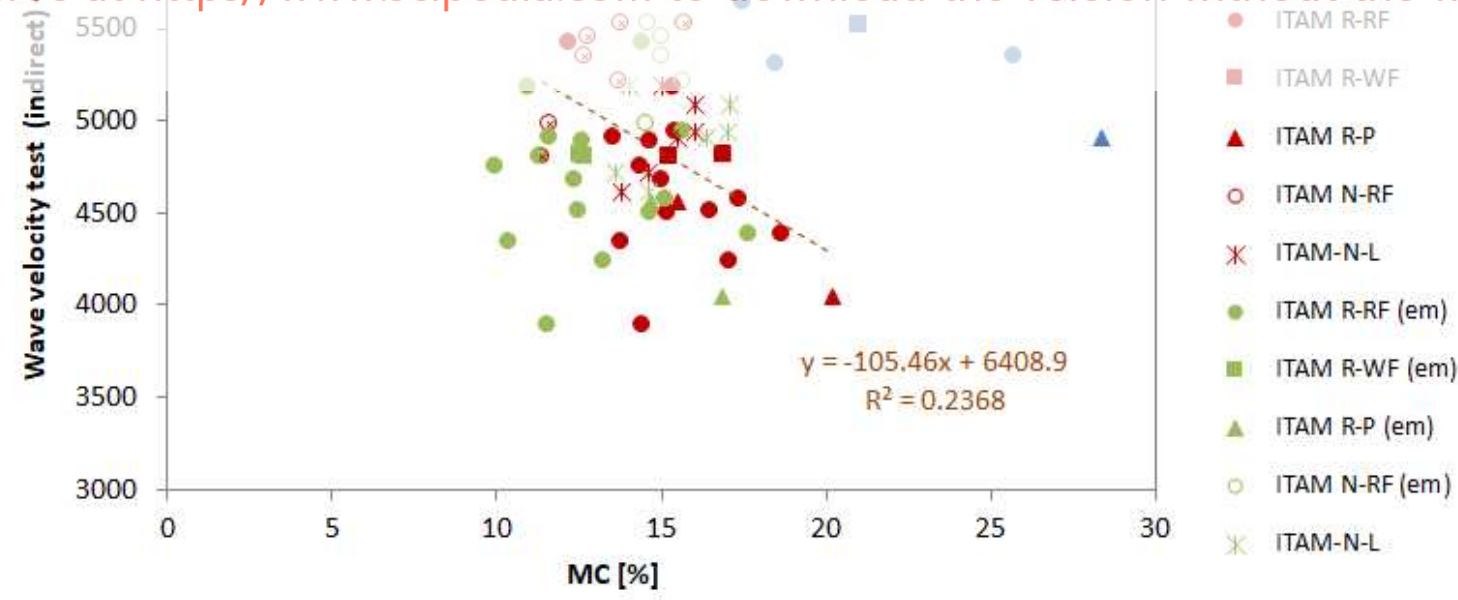

Figure 10: Comparison of WV (indirect tests) results and MC on corresponding pairs of UNIPD and ITAM measurements 


\section{CONCLUSIONS}

An experimental research was carried out in collaboration among three research groups to investigate the effect of different devices for the measurements of moisture content on various species of timber elements in either new or old conditions. Especially retrieved elements had high MC to take into consideration worse onsite conditions in existing buildings.

Results showed that:

- $\quad$ Electrical and electromagnetic devices for surface MC measurements used by ITAM are comparable methods. Pin meters going more deep from the surface (e.g. device used by UNIPD) showed an increase of MC ranging from 32\% (R-WF elements) to $64 \%$ (N-L elements).

- Although the large variation of MC values, resistance drilling methods were not affected by the MC of the tested wood. However, preventive conditioning of wood is always suggested, when possible, in order to even the current state out.

- $\quad$ Pin penetration tests applied in timber elements (UNIPD) with high MC was problematic (no application following the protocol of five blows was possible in most cases) and no significant correlations were found.

- $\quad$ Pin pushing (ITAM) as well as all other penetration resistance methods are strongly influenced by the density and the structure of the wood, i.e. by the species and the condition or the degradation state of wood. This fact suppresses the influence of the moisture content on the measurements. The results confirm the MC effect discovered in [6], i.e. a slight increase of the resistance against pushing the needle through the cross-section with an increase of the MC between the values of $10 \%$ to $20 \%$.

- The lowest dispersion of data was detected for the combination of MC and the results of wave velocity-based tests. A decreasing trend of velocity according to increases of MC was confirmed. especially in the case of indirect wave transmission configuration. Future developments of the research will extend the dataset to improve relationships among the variables under study and will be aimed at investigating the possible correlation among ND/MD and destructive tests on real-scale timber elements to calibrate mechanical parameters.

Acknowledgements. The authors wish to thank Bozza s.r.l. for the availability of timber elements and space for the experimental tests. The research was partially funded by the Italian project Corewood POR FESR Veneto 2014-2020.

\section{REFERENCES}

[1] Riggio, M., Anthony, R.W., Augelli, F., Kasal, B., Lechner T., Muller, W. and Tannert, T. In situ assessment of structural timber using non-destructive techniques. Materials an Structures, 47(5) (2013), pp 749-766.

[2] Piazza, M. and Riggio, M. Visual strength-grading and NDT of timber in traditional structures. Journal of Building Appraisal, 3 (2008), pp. 267-296.

[3] Tannert, T., Anthony, R.W., Kasal, B., Kloiber, M., Piazza, M., Riggio, M., Rinn, F., Widmann, R., Yamaguchi, N. In situ assessment of structural timber using semidestructive techniques. Materials and Structures, 47(5) (2013), pp 767-785. 
[4] Drdácký, M. and Kloiber, M. In-situ compression stress-deformation measurements along the timber depth profile. Advanced Materials Research, 778 (2013), pp. 209-216,

[5] Kloiber, M., Drdácký, M., Tippner, J. and Hrivnák, J. Conventional compressive strength parallel to the grain and mechanical resistance of wood against pin penetration and microdrilling established by in-situ semidestructive devices. Materials and Structures, 48 (2015), pp. 3217-3229.

[6] Tippner, J., Kloiber, M., Sebera, V., Kunecký, J.: Health diagnostics of timber by continual pushing-through method. In: 17th International Conference on Experimental Mechanics (ICEM 17), 7/2016, Rhodes, Greece.

[7] Kloiber, M., Drdácký, M., Kunecký, J., Sebera, V., Tippner, J.: Mini-jack based direct determination of wood mechanical characteristics in situ. In: 17th International Conference on Experimental Mechanics (ICEM 17), 7/2016, Rhodes, Greece.

[8] Knag, H., Booker, R.E.: Variation of stress wave velocity with MC and temperature. Wood Science and Technology 36 (2002) 41-54 Springer-Verlag 2002, DOI 10.1007/s00226001-0129-X

[9] UNI EN 338:2016 Structural timber - Strength classes.

[10] UNI 11119:2004 Cultural Heritage. Wooden artefacts. Load-bearing structures - On site inspections for the diagnosis of timber members.

[11] Uzielli, L. Il manuale del legno strutturale. Ispezione e diagnosi in opera. Mancosu, Vol. 1 (2006).

[12] Dackermann, U., Elsener, R., Li, J. and Crews, K. A comparative study of using static and ultrasonic material testing methods to determine the anisotropic material properties of wood. Construction and Building Materials, 102 (2016), pp. 963-976. 